\title{
Literacy programs efficacy for developing children's early reading skills in familiar language in Zambia
}

\section{Sampa, Francis K.}

2018

Sampa , F K , Ojanen , E , Westerholm , J , Ketonen , R \& Lyytinen , H 2018 , ' Literacy programs efficacy for developing children's early reading skills in familiar language in Zambia ' , Journal of Psychology in Africa , vol. 28 , no. 2 , pp. 128-135 . https://doi.org/10.1080/14330237.2018.143

http://hdl.handle.net/10138/308897

https://doi.org/10.1080/14330237.2018.1435050

unspecified

acceptedVersion

Downloaded from Helda, University of Helsinki institutional repository.

This is an electronic reprint of the original article.

This reprint may differ from the original in pagination and typographic detail.

Please cite the original version. 


\title{
Literacy Programs Efficacy for Developing Children's Early Reading Skills in Familiar Language in Zambia
}

\author{
Francis K. Sampa ${ }^{1}$, Emma Ojanen ${ }^{2}$, Jari Westerholm³ ${ }^{3}$ Ritva Ketonen ${ }^{4}$, Heikki Lyytinen ${ }^{2}$, \\ ${ }^{1}$ Read To Succeed, Zambia; ${ }^{2}$ Department of Psychology, University of Jyväskylä, Finland, \\ ${ }^{3}$ Niilo Mäki Institute, Jyväskylä, Finland, ${ }^{4}$ Faculty of Educational Sciences, University of \\ Helsinki, Finland
}

Corresponding author: Francis K. Sampa, sampafrancis@gmail.com, +260 977606519

\section{Abstract}

This study investigated the comparative efficacy of a phonics based reading program and a language experience approach based literacy program to develop reading skills among Zambian early childhood school learners. The learners ( $\mathrm{n}=1,986$; Grade 2 level, (females $=50.1 \%$ ) took either the phonics based reading program $(n=1,593)$ or the alternative language experience approach based program $(\mathrm{n}=393)$. They were all assessed for reading skills utilizing the Early Grade Reading Assessment test (EGRA) in four languages (Cinyanja, Icibemba, Kiikaonde and Silozi). Results suggest that learners in phonics based literacy program were significantly better in letter-sound knowledge in all the four languages and in reading skills (non-word reading, oral passage reading and reading comprehension) only in Icibemba and Silozi compared to those who took the alternative program. Results reveal that children in PLP had significantly better performance in most reading skills than in PRP, but the effect sizes were small or medium. The high floor effect in all directly reading-related measures is an indication that most children in Zambia have not acquired even the basic reading skill of the transparently written language they are familiar with in neither PRP nor PLP and thus are in urgent need of better instruction. The implementation of the phonics approach is not effective enough. Instruction of the sounds of letters requires special attention where digital training tools (such as GraphoGame) may provide the most effective help to both teachers and children.

Keywords: Early Grade Reading Assessment (EGRA), Familiar language, Reading skills, Primary Literacy Program, Bantu languages, Transparent orthography, Language of instruction. 
Use of the familiar language for early literacy acquisition is an international standard and especially well founded among readers whose familiar language is transparent (Aro \& Wimmer 2003; Seymour, Aro \& Erskine, 2003). This practice has been adopted in Zambian school settings and evidence is needed on the efficacy of the Zambian implementation of reading acquisition programs utilizing familiar language for literacy instruction (Tambulukani \& Bus, 2011, Ojanen et al., 2013, Serpell, 2014). Familiarity of the language of instruction, and its effect on learning to read is supported by many studies (e.g., Kaani \& Joshi, 2013, Matafwali \& Bus, 2013, Tambulukani \& Bus, 2011, Ojanen et al., 2013, Serpell, 2014). This study compares the efficacy of a phonics based reading instruction program and an alternative language experience approach based program for the acquisition of reading skills by the second grade learners in Zambia.

Zambia has adopted the Primary Reading Program (PRP) and the Primary Literacy Program (PLP) for literacy instruction in the early grades in seven familiar indigenous languages; Cinyanja, Icibemba, Chitonga, Kiikaonde, Silozi, Lunda and Luvale. According to the Global Monitoring Report (2016), most children in Africa learn and take school examinations in languages that they do not speak at home and this may hinder their progress in reading and affect their performance in reading tests.

The Primary Reading Program (PRP, implemented from 1999 to 2013) is a language experience program in which learners acquire literacy for reading and writing by building on the oral language that they have already acquired. The Primary Literacy Program (PLP) is a phonicsbased reading program in which learners are meant to acquire literacy by learning letter-sound 
connections in familiar language. Learners begin to learn first the five vowels and then to blend these with consonants to form syllables and words. Clark (2013) described the phonics-based approach as focusing on decoding process where learners are taught to break written language down into small and simple components and identify and store letters with the sounds these represent and learn to assemble the sounds together according to sequences of letters.

According to Taylor (2000) the language experience approach (LEA) promotes reading and writing through the use of personal experiences and oral language. It enables beginner readers to relate their experiences to reading and writing. The LEA approach is a holistic approach that enables the teacher and the learners to discuss experience, allow learners to express their own ideas, a teacher to models the sound of fluent expressive reading and learners begin to recognize specific words from account and develop decoding skills. In the LEA learners do not breakdown sounds individually but take words at face value and associate them with prior knowledge. According to Hall (1970) in LEA materials are learner generated and all communication skills (reading, writing, listening, and speaking) are integrated. The difficulty of vocabulary and grammar are determined by learner's own use and learning and teaching are personalized, communicative and creative. Therefore, in LEA based approach, materials have familiar vocabulary and ideas are more meaningful to the learners than the phonics-based approach which is centered on letter-sounds and their assembly.

The aim of this study is to compare the relative efficacy of a phonics based and language experience based to teaching early literacy to Zambian early graders. The research question 
was: What is the comparative efficacy of phonics based program and language experience based program in teaching reading to Zambian early childhood learners with linguistic diversity?

\section{Method}

\section{Participants and setting}

A total of 1,986 early childhood school learners (995 girls and 991 boys) were randomly sampled from 200 schools of 16 Zambian school districts. Samples for the PRP study comprised 393 learners (196 females and 197 males) from 40 schools, randomly selected from 4 districts. During PRP, familiar language was used for learning to read for one year in grade 1 and children transitioned to learn to read in English from grade 2, the end of which was the assessment time for the present study, and continued to consolidate their reading skills in familiar language during Zambian language lessons. The samples for the study for PLP comprised 1,593 learners (799 females and 794 males) from 160 schools randomly selected from 12 districts. During PLP, familiar language was used for learning to read from Grade 1 to the end of Grade 2 and only oral English was introduced in Grade 2, the end of which was the assessment time for the present study.

\section{Materials}

The data on the children's reading acquisition were collected utilizing the Early Grade Reading Assessment (RTI, 2012). It assesses the following five components in familiar language: lettersound knowledge, unfamiliar word oral reading fluency, connected text oral reading fluency, reading comprehension and listening comprehension. 
Orientation to print: Each of the participants was shown a written paragraph segment in the learner's stimuli packet. The test administrator asked the participant to point on the paper where s/he would begin to read, the direction of reading and at the end of the line, where the learner would read next. The test was conducted in 60 seconds. The maximum score was 3 points.

Letter sound knowledge: Learners were given 60 seconds in which to sound out as many letter sounds as possible (not those used in the recitation of English letter names) selected in the familiar language. Letters only occurring in loan words were excluded. The test involved beginning from the first row, moving from left to right across the page to the last tenth row with a total of 100 letters (some repeated) on display. For example, the first row of test items in Cinyanja EGRA test in 2014 was $m N A J K u I \mathrm{~km}$ and $d$. The assessor specifically instructed the child to give the sounds of the letters and not letter names. Letter names given as answers were scored zero. The EGRA assessors were trained to score the letter-sounds in a consistent way by agreeing beforehand what pronunciations of the sounds are correct. Some letters were in lower case while others were in upper case but there was no balance in total between amount of upper- and lower-case letters in every row. Practice items (A, P, L) were administered before the test. The test was discontinued if a learner scored all letters incorrectly on the first line or when the timer reached 60 seconds. If a child hesitated or stopped on a letter for 3 seconds, the assessor asked the child to read the next letter and then the by-passed letter was marked as incorrect.

Non-Word Decoding: Learners were given 60 seconds to read 50 orthographically correct nonword items as carefully as possible, reading across the page. Words in this test started with any 
of the letters of a familiar language (not those used in loan words only) and contained at least two subsequent letters, most with more, from three to six letters, and the length of words were mixed in each row. For example, the first line in one of the EGRA versions contained the following words for Cinyanja: kelo, nipe, gelu, atapi, mdzimu. The non-words were different in each language version. For each non-word read, a child scored 1 point. The test was discontinued if a learner failed to read any of the items in the first row. This sub-test included a set of practice items before the actual test (oli, koki, cota).

Oral passage reading: Instructions were given to the child about reading aloud a short passage within a stipulated time. The story comprised 7 sentences in Cinyanja and Kiikaonde, 6 sentences in Icibemba and 5 sentences in Silozi. The learner was assessed according to the number of words read correctly within 60 seconds out of 40 words for Cinyanja, 47 words for Icibemba, 56 words for Kiikaonde and 32 words for Silozi. The test was stopped if the child did not read a single correct word of the first sentence which contained six words for Cinyanja, Kiikaonde and Silozi and nine words for Icibemba.

Reading comprehension: This test assessed the learner's ability to understand what was read by answering questions based on the passage read in Oral passage reading. After the oral passage reading, the child was asked to answer oral questions (where, what, why, who, how). This was to test the learners' basic understanding of the story and no more than 15 seconds was allocated to answering of each question. There were five questions asked about the story, each carrying 1 mark for a total of 5 points. If the learner did not read correctly the first sentence and time was not enough for reading all sentences, the 5 questions were not asked. 
Listening comprehension: This test assessed the learner's ability to follow and understand a simple orally delivered story containing 62 words for Cinyanja, 77 words for Icibemba, 47 words for Kiikaonde and 65 words for Silozi. The test also required the learners to concentrate and focus in order to understand and remember enough about the story read by the assessor and then to answer both literal and inferential questions without asking for repetition of the story. A child was asked to answer 5 questions based on the short text. In this assessment, a learner was allocated no more than 30 seconds in which to answer each question. Each question carried 1 mark and the total was 5 points.

The EGRA is available in four languages, Cinyanja, Icibemba, Kiikaonde and Silozi. The EGRA test results for 2014 were used to find out the levels of reading skills obtained by children in familiar language by end of Grade 2 . Table 1 shows the variables that were tested in Cinyanja, Icibemba, Kiikaonde and Silozi and their theoretical maximum scores. The reliability scores from the EGRA for each assessment type by language were: Chitonga .74, Cinyanja .82, Icibemba .80, Kiikaonde .80, Lunda .87, Luvale .75 and Silozi .82 (RTI, 2015). An alpha score over 0.70 is acceptable and a value over 0.80 is considered to be very good. In addition, construct validity was assessed by examining the item hierarchy, or the ordering of items within a subtask from easy to difficult that result from an item level analysis and word length during the Rasch measurement (RTI, 2015). 
TABLE 1 maximum score for PRP and PLP for each variable

\begin{tabular}{lcccc}
\hline \multicolumn{1}{c}{ Task: } & Cinyanja & \multicolumn{3}{c}{ Theoretical maximum scores } \\
& Icibemba & Kiikaonde & Silozi \\
\hline Orientation to print & 3 & 3 & 3 & 3 \\
Letter-sound knowledge & 100 & 100 & 100 & 100 \\
Non word decoding & 50 & 50 & 50 & 50 \\
Oral passage reading & 40 & 47 & 56 & 32 \\
Reading comprehension & 5 & 5 & 5 & 5 \\
Listening comprehension & 5 & 5 & 5 & 5 \\
\hline
\end{tabular}

\section{Procedures}

Permission for the study was granted by the Ministry of General Education. The selection of learners was done at each school by random sampling using Grade 2 registers. The sample size comprised 10 Grade 2 learners (5 boys; 5 girls) per classroom in each district. The learners took the reading literacy tests during normal school hours.

\section{Data Analysis}

Data analyses were conducted by using SPSS version 22. The hypothesis of normality was rejected because of high skewness and huge zero peak in the variables letter-sound knowledge, non-word decoding, oral passage reading and reading comprehension. Orientation to print had a clear ceiling effect. Listening comprehension was the only variable in which the distribution of PRP-related scores was rather close to normal. For these reasons, Mann-Whitney U test, a nonparametric test was used to compare levels of reading skills. In this study, there were missing values and the 'missingness' varied within test languages between $.0-.8$ percentages and within programs from .0 to .3 percentages which was much lower than the thumb rule of $5-10 \%$ (Dong 
\& Peng, 2013). As such, this very low missingness level was assumed not to practically affect the results very much. Little's MCAR test result still rejected the assumption of missing completely at random (MCAR) in all languages except in Silozi. The corresponding test results were Cinyanja $(\chi 2=25.229, \mathrm{df}=5, \mathrm{p}<.001)$, Icibemba $(\chi 2=26.795, \mathrm{df}=4, \mathrm{p}<.001)$, Kiikaonde $(\chi 2=32.355, \mathrm{df}=4, \mathrm{p}<.001)$ and Silozi $(\chi 2=2.147, \mathrm{df}=10, \mathrm{p}=.995)$. Rejecting the assumption of MCAR might cause biased estimates in all test language results except in Silozi when using list wise deletion with the analyses, but because the general level of missingness was such low the effect of missingness will be assumed as minor.

The high number of zero scores limited the selection of analysis methods. The number of zero scorers was high in both Primary Reading Program and Primary Literacy Program except for Orientation to Print and Listening Comprehension, which are both not written language features. To give a quick insight to the severe problem of zero scorers' existence in the data language wise comparisons were proceeded between the programs. The comparisons were done using The Significance of the Difference Between Two Independent Proportions, z-ratio test application from VassarStats website (Lowry, 2016). Table 2 shows the proportion of zero scorers of the two programs in all measured reading skill variables for Cinyanja, Icibemba, Kiikaonde and Silozi. The results showed significant differences in proportions of zero scorers between the programs favoring PLP in all languages. The effect sizes were small in Icibemba and Silozi and less than small in Cinyanja and Kiikaonde. 
TABLE 2. Testing the proportions of zero scorers over all research variables between the programs

\begin{tabular}{|c|c|c|c|c|c|c|c|c|c|}
\hline & & \multicolumn{2}{|c|}{ Cinyanja } & \multicolumn{2}{|c|}{ Icibemba } & \multicolumn{2}{|c|}{ Kiikaonde } & \multicolumn{2}{|c|}{ Silozi } \\
\hline Program & & & $\begin{array}{c}\text { Proportion } \\
(\%)\end{array}$ & & $\begin{array}{c}\text { Proportion } \\
(\%)\end{array}$ & & $\begin{array}{c}\text { Proportion } \\
(\%)\end{array}$ & & $\begin{array}{c}\text { Proportion } \\
(\%)\end{array}$ \\
\hline \multirow[t]{2}{*}{ PRP } & Freq 0 & 275 & 46,3 & 321 & 54,0 & 306 & 53,3 & 336 & 56,8 \\
\hline & Total & 594 & & 594 & & 574 & & 592 & \\
\hline \multirow[t]{7}{*}{ PLP } & Freq 0 & 879 & 37,4 & 841 & 35,0 & 1113 & 46,5 & 940 & 39,2 \\
\hline & Total & 2351 & & 2402 & & 2394 & & 2400 & \\
\hline & $\begin{array}{c}\text { pPRP- }^{-} \\
\text {pPLP }=p_{\text {diff }}\end{array}$ & .089 & & .19 & & .068 & & .176 & \\
\hline & $\mathrm{Z}^{*}$ & 3.974 & & 8.522 & & 2.937 & & 7.751 & \\
\hline & sig & $<.0002$ & & $<.0002$ & & .003 & & $<.0002$ & \\
\hline & sig adj. $* *$ & $<.0006$ & & $<.0006$ & & .003 & & $<.0006$ & \\
\hline & $\mathrm{r} * * *$ & 0,07 & & 0,16 & & 0,05 & & 0,14 & \\
\hline
\end{tabular}

* Standard binomial requirement: $\mathrm{n}(\mathrm{p})$ and $\mathrm{n}(1-\mathrm{p})$ must both be equal to or greater than 5 .

** $p_{\text {adj }}$ adjustment was done with $\mathrm{R}$ to avoid Type I error by following the Holm procedure (1979). In case of $\mathrm{p}<.001$, the calculation was done with the p-value of .0005.

$* * * \mathrm{r}=\mathrm{z} /(\sqrt{ } \mathrm{N})($ Field, 2009), Cohen (1992): Effect size $(r): .1 \leq r<.3$ small, $.3 \leq r<.5$ medium, $r \geq .5$ large effects

\section{RESULTS}

Program comparisons: The data on reading program type and the reading skill variables for each learning language are shown in Table 3.

Table 3: Comparison of PRP and PLP mean rank scores in all test languages separately

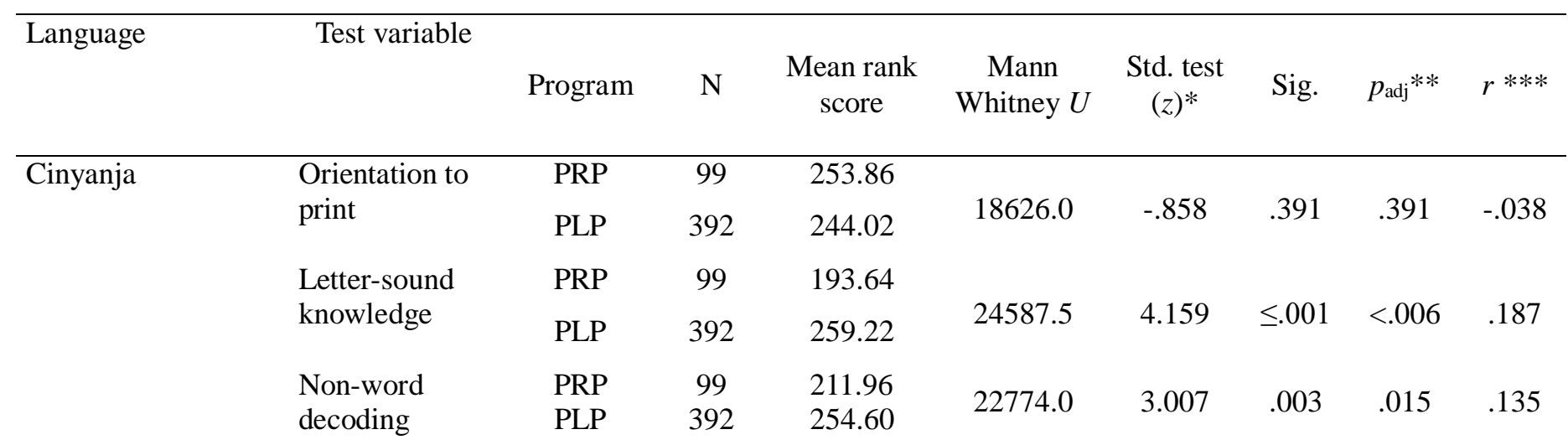




\begin{tabular}{|c|c|c|c|c|c|c|c|c|c|}
\hline & \multirow{2}{*}{$\begin{array}{l}\text { Oral passage } \\
\text { reading }\end{array}$} & PRP & 99 & 222.87 & \multirow{2}{*}{21693.5} & \multirow{2}{*}{2.072} & \multirow{2}{*}{.038} & \multirow{2}{*}{.128} & \multirow{2}{*}{.094} \\
\hline & & PLP & 392 & 251.84 & & & & & \\
\hline & \multirow{2}{*}{$\begin{array}{l}\text { Reading } \\
\text { comprehension }\end{array}$} & PRP & 99 & 225.12 & \multirow[b]{2}{*}{21471.5} & \multirow[b]{2}{*}{2.147} & \multirow[b]{2}{*}{.032} & \multirow[b]{2}{*}{.128} & \multirow[b]{2}{*}{.097} \\
\hline & & PLP & 392 & 251.27 & & & & & \\
\hline & \multirow{2}{*}{$\begin{array}{l}\text { Listening } \\
\text { comprehension }\end{array}$} & PRP & 99 & 269.04 & \multirow{2}{*}{17024.0} & \multirow{2}{*}{-1.924} & \multirow{2}{*}{.054} & \multirow{2}{*}{.128} & \multirow{2}{*}{-.087} \\
\hline & & PLP & 391 & 239.54 & & & & & \\
\hline \multirow[t]{12}{*}{ Icibemba } & \multirow{2}{*}{$\begin{array}{l}\text { Orientation to } \\
\text { print }\end{array}$} & PRP & 99 & 200.86 & \multirow{2}{*}{24764.0} & \multirow{2}{*}{4.277} & \multirow[b]{2}{*}{$<.001$} & \multirow{2}{*}{$<.006$} & \multirow{2}{*}{.194} \\
\hline & & PLP & 401 & 262.76 & & & & & \\
\hline & \multirow{2}{*}{$\begin{array}{l}\text { Letter-sound } \\
\text { knowledge }\end{array}$} & PRP & 99 & 184.82 & \multirow{2}{*}{26351.5} & \multirow{2}{*}{5.065} & & & \\
\hline & & PLP & 401 & 266.71 & & & $<.001$ & $<.006$ & .230 \\
\hline & Non-word & PRP & 99 & 163.55 & & & & & \\
\hline & decoding & PLP & 401 & 271.97 & 28458.0 & 7.051 & $<.001$ & $<.006$ & .321 \\
\hline & Oral passage & PRP & 99 & 192.14 & & & & & \\
\hline & reading & PLP & 399 & 263.73 & 25429.0 & 5.079 & $<.001$ & $<.006$ & .231 \\
\hline & Reading & PRP & 99 & 217.65 & & & & & \\
\hline & comprehension & PLP & 399 & 257.40 & 22903.5 & 3.548 & $<.001$ & $<.006$ & .161 \\
\hline & Listening & PRP & 99 & 245.35 & & & & & \\
\hline & comprehension & PLP & 401 & 251.77 & 20359.0 & .405 & .685 & .685 & .018 \\
\hline Kiikaonde & Orientation to & PRP & 96 & 243.19 & & & & & \\
\hline & print & PLP & 400 & 249.77 & 19709.5 & .573 & .567 & 1.0 & .026 \\
\hline & Letter-sound & PRP & 96 & 199.32 & & & & & \\
\hline & knowledge & PLP & 400 & 260.30 & 23921.0 & 3.780 & $<.001$ & $<.006$ & .172 \\
\hline & Non-word & PRP & 96 & 234.69 & & & & & \\
\hline & & PLP & 400 & 251.82 & 20526.0 & 1.383 & .167 & .668 & .063 \\
\hline & Oral passage & PRP & 95 & 248.26 & & & & & \\
\hline & reading & PLP & 397 & 246.08 & 18690.5 & -.286 & .775 & 1.0 & -.013 \\
\hline & Reading & PRP & 95 & 232.97 & & & & & \\
\hline & comprehension & PLP & 397 & 249.74 & 20142.5 & 1.690 & .091 & .455 & .077 \\
\hline & Listening & PRP & 96 & 246.25 & & & & & \\
\hline & comprehension & PLP & 400 & 249.04 & 19416.0 & .176 & .860 & 1.0 & .039 \\
\hline Silozi & Orientation to & PRP & 99 & 222.61 & & & & & \\
\hline & & PLP & 400 & 256.78 & 22512.0 & 2.451 & .014 & .014 & .111 \\
\hline & $\begin{array}{l}\text { Letter-sound } \\
\text { knowledge }\end{array}$ & $\begin{array}{l}\text { PRP } \\
\text { PLP }\end{array}$ & $\begin{array}{c}99 \\
400\end{array}$ & $\begin{array}{l}188.36 \\
265.26\end{array}$ & 25902.5 & 4.954 & $<.001$ & $<.006$ & .225 \\
\hline
\end{tabular}




$\begin{array}{lcccccccc}\begin{array}{l}\text { Non-word } \\ \text { decoding }\end{array} & \text { PRP } & 98 & 205.03 & & & & & \\ \text { Oral passage } & \text { PLP } & 400 & 260.40 & 23958.0 & 3.857 & <.001 & <.006 & .175 \\ \text { reading } & \text { PRP } & 99 & 203.80 & & & & & \\ \text { Reading } & \text { PLP } & 400 & 261.44 & 24374.0 & 4.066 & <.001 & <.006 & .185 \\ \text { comprehension } & \text { PRP } & 99 & 209.52 & & & & & \\ \text { Listening } & \text { PLP } & 400 & 260.02 & 23808.0 & 4.047 & <.001 & <.006 & .184 \\ \text { comprehension } & \text { PRP } & 98 & 196.22 & & & & & \\ & \text { PLP } & 400 & 262.55 & 24821.0 & 4.210 & <.001 & <.006 & .191\end{array}$

* Standard binomial requirement: $\mathrm{n}(\mathrm{p})$ and $\mathrm{n}(1-\mathrm{p})$ must both be equal to or greater than 5 .

** $p_{\text {adj }}$ adjustment was done with $\mathrm{R}$ to avoid Type I error by following the Holm procedure (1979). In case of $\mathrm{p}<.001$, the calculation was done with the $\mathrm{p}$-value of .0005

$* * * \mathrm{r}=\mathrm{z} /(\sqrt{\mathrm{N}})$ (Field, 2009), Cohen (1992): Effect size $(r): .1 \leq r<.3$ small, $.3 \leq r<.5$ medium, $r \geq .5$ large effects

As can be observed from Table 3, Cinyanja learners in PLP obtained significantly higher mean rank scores in letter-sound knowledge and non-word decoding. The differences were significant with small effect sizes. Overall, the results could be interpreted as weakly supporting PLP efficacy in teaching reading to children in Cinyanja. In Icibemba, learners in PLP obtained higher mean rank scores in all variables and the differences were significant except in listening comprehension. The effect sizes were small, except in non-word decoding where the effect size was medium. Overall, the results could be interpreted as supporting use of PLP in teaching reading to children in Icibemba. For Kiikaonde speaking children, the results showed that learners in PLP obtained significantly higher mean rank scores only in letter-sound knowledge, with small effect size. Overall, the results could be interpreted as very weakly supporting use of PLP in Kiikaonde. In Silozi, learners in PLP obtained higher mean rank scores in all variables and the differences were all significant with small effect sizes. Overall, the results for reading skill acquisition in Silozi could be interpreted as supporting use of PLP.

\section{Home language effects}


Results for comparison of the differences between the two programs when home language was equal to language of instruction are shown in Table 4.

Table 4: Comparison of PRP and PLP mean rank scores when Home language was equal to Test language

\begin{tabular}{|c|c|c|c|c|c|c|c|c|c|}
\hline Language & Variable & Program & $\mathrm{N}$ & $\begin{array}{l}\text { Mean } \\
\text { rank } \\
\text { score }\end{array}$ & $\begin{array}{c}\text { Mann } \\
\text { Whitney }\end{array}$ & $\begin{array}{l}\text { Std. test } \\
(\mathrm{z})^{*}\end{array}$ & Sig & $p_{\text {adj }} * *$ & $\mathrm{r} * * *$ \\
\hline \multirow[t]{12}{*}{ Cinyanja } & \multirow{2}{*}{$\begin{array}{l}\text { Orientation to } \\
\text { print }\end{array}$} & PRP & 77 & 112.23 & \multirow[t]{2}{*}{4525.0} & \multirow[t]{2}{*}{-1.756} & \multirow[t]{2}{*}{.079} & \multirow[t]{2}{*}{.158} & \multirow[t]{2}{*}{-.122} \\
\hline & & PLP & 132 & 100.78 & & & & & \\
\hline & Letter-sound & PRP & 77 & 88.08 & \multirow[t]{2}{*}{6385.0} & \multirow[t]{2}{*}{3.141} & \multirow[t]{2}{*}{.002} & \multirow[t]{2}{*}{.012} & \multirow[t]{2}{*}{.217} \\
\hline & knowledge & PLP & 132 & 114.87 & & & & & \\
\hline & Non-word & PRP & 77 & 91.70 & \multirow[t]{2}{*}{6106.0} & \multirow[t]{2}{*}{2.777} & \multirow[t]{2}{*}{.005} & \multirow[t]{2}{*}{.025} & \multirow[t]{2}{*}{.192} \\
\hline & decoding & PLP & 132 & 112.76 & & & & & \\
\hline & Oral passage & PRP & 77 & 95.66 & \multirow[t]{2}{*}{5801.0} & \multirow[t]{2}{*}{1.971} & \multirow[t]{2}{*}{.049} & \multirow[t]{2}{*}{.147} & \multirow[t]{2}{*}{.136} \\
\hline & reading & PLP & 132 & 110.45 & & & & & \\
\hline & Reading & PRP & 77 & 94.40 & \multirow[t]{2}{*}{5898.0} & \multirow[t]{2}{*}{2.555} & \multirow[t]{2}{*}{.011} & \multirow[t]{2}{*}{.044} & \multirow[t]{2}{*}{.177} \\
\hline & comprehension & PLP & 132 & 111.18 & & & & & \\
\hline & Listening & PRP & 77 & 110.16 & 4684.5 & -.982 & .326 & .326 & .068 \\
\hline & comprehension & PLP & 132 & 101.99 & & & & & \\
\hline Icibemba & Orientation to & PRP & 99 & 168.82 & 20412.0 & 4.564 & $<.001$ & $<.003$ & .223 \\
\hline & print & PLP & 325 & 225.81 & & & & & \\
\hline & Letter-sound & PRP & 99 & 156.12 & 29669.5 & 5.244 & $<.001$ & $<.003$ & .255 \\
\hline & knowledge & PLP & 325 & 229.68 & & & & & \\
\hline & Non-word & PRP & 99 & 130.82 & 24174.0 & 7.894 & $<.001$ & $<.003$ & .383 \\
\hline & decoding & PLP & 325 & 237.38 & & & & & \\
\hline & Oral passage & PRP & 99 & 157.80 & 21305.0 & 5.654 & $<.001$ & $<.003$ & .276 \\
\hline & reading & PLP & 323 & 227.96 & & & & & \\
\hline & Reading & PRP & 99 & 181.92 & 18917.0 & 3.889 & $<.001$ & $<.003$ & .189 \\
\hline & comprehension & PLP & 323 & 220.57 & & & & & \\
\hline & Listening & PRP & 99 & 205.12 & 16818.0 & .700 & .484 & .484 & .034 \\
\hline & comprehension & PLP & 325 & 214.75 & & & & & \\
\hline Kiikaonde & Orientation to & PRP & 91 & 165.88 & 12022.5 & 0.993 & .321 & .963 & .054 \\
\hline & print & PLP & 252 & 174.21 & & & & & \\
\hline & Letter-sound & PRP & 91 & 146.05 & 13827.0 & 2.948 & .003 & .018 & .160 \\
\hline & knowledge & PLP & 252 & 181.37 & & & & & \\
\hline & Non-word & PRP & 91 & 166.29 & 11986.0 & 0.878 & .380 & .963 & .047 \\
\hline & decoding & PLP & 252 & 174.06 & & & & & \\
\hline & Oral passage & PRP & 91 & 173.18 & 11176.5 & -0.536 & .592 & .963 & -.029 \\
\hline & reading & PLP & 250 & 170.21 & & & & & \\
\hline & Reading & PRP & 91 & 164.16 & 11997.0 & 1.314 & .189 & .756 & .071 \\
\hline & comprehension & PLP & 250 & 173.49 & & & & & \\
\hline
\end{tabular}




\begin{tabular}{|c|c|c|c|c|c|c|c|c|c|}
\hline & $\begin{array}{l}\text { Listening } \\
\text { comprehension }\end{array}$ & $\begin{array}{l}\text { PRP } \\
\text { PLP }\end{array}$ & $\begin{array}{l}91 \\
252 \\
\end{array}$ & $\begin{array}{l}152.14 \\
179.17\end{array}$ & 13273.0 & 2.314 & .021 & .105 & .125 \\
\hline \multirow[t]{13}{*}{ Silozi } & \multirow{2}{*}{$\begin{array}{l}\text { Orientation to } \\
\text { print }\end{array}$} & PRP & 44 & 198.98 & 8471.0 & 0.556 & .578 & 1.0 & .028 \\
\hline & & PLP & 369 & 207.96 & & & & & \\
\hline & Letter-sound & PRP & 44 & 154.77 & 10416.0 & 3.176 & .001 & .006 & .159 \\
\hline & knowledge & PLP & 369 & 213.23 & & & & & \\
\hline & \multirow{2}{*}{$\begin{array}{l}\text { Non-word } \\
\text { decoding }\end{array}$} & PRP & 44 & 177.91 & 9398.0 & 1.881 & .060 & .240 & .094 \\
\hline & & PLP & 369 & 210.47 & & & & & \\
\hline & \multirow{2}{*}{$\begin{array}{l}\text { Oral passage } \\
\text { reading }\end{array}$} & PRP & 44 & 175.53 & 9502.5 & 2.051 & .040 & .200 & .103 \\
\hline & & PLP & 369 & 210.75 & & & & & \\
\hline & \multirow{2}{*}{$\begin{array}{l}\text { Reading } \\
\text { comprehension }\end{array}$} & PRP & 44 & 185.33 & 9071.5 & 1.573 & .116 & .348 & .079 \\
\hline & & PLP & 369 & 209.58 & & & & & \\
\hline & \multirow{2}{*}{$\begin{array}{l}\text { Listening } \\
\text { comprehension }\end{array}$} & PRP & 44 & 212.00 & 7898.0 & -0.304 & .761 & 1.0 & -.015 \\
\hline & & PLP & 369 & 206.40 & & & & & \\
\hline & $\begin{array}{r}* \text { Stan } \\
* * p_{\mathrm{ad}} \\
(1979) \\
* * * \mathrm{r}= \\
\text { mediu }\end{array}$ & d binc & ects & ohen $(1$ & : Effect & $(r): .1$ & $\begin{array}{l}\text { le of } \\
.3 \mathrm{sm}\end{array}$ & great & $\begin{array}{l}\text { an } 5 . \\
\text { dure }\end{array}$ \\
\hline
\end{tabular}

As shown in Table 4, learners who used Cinyanja as their home language for reading instruction obtained higher mean rank scores in PLP compared to PRP in letter-sound knowledge, nonword decoding and in reading comprehension with small effect sizes. Learners who used Icibemba as their home language for reading instruction obtained higher mean rank scores in PLP in all reading skills variables. The differences were significant in orientation to print, lettersound knowledge, oral passage reading and reading comprehension with small effect sizes and in non-word decoding with a medium effect size. Results also show that learners in PLP who used Kiikaonde as their home language for reading instruction obtained significantly higher mean rank scores compared to those in PRP only in letter-sound knowledge with small effect size. Similarly, learners who used Silozi as home language for reading instruction obtained significantly higher mean rank scores in favor of PLP only in letter-sound knowledge with small effect size. 


\section{DISCUSSION}

The early childhood learners taking PLP performed relatively better in reading skills acquisition than those taking PRP. This might be explained by the fact that Zambian languages contain grapheme-phoneme correspondences that behave consistently. This facilitates reading words on the basis of grapheme-phoneme correspondences that is sufficient for accurate word recognition (Aro, 2004). All indigenous African languages are relatively new and thus transparent orthographies (Serpell \& Simatende, 2016). For example, the vowels $A, E, I, O$, and $U$, which behave very inconsistently in English, are represented in Bantu languages in a consistent manner. This makes initial literacy learning much easier than it is in English, where each of the vowels may represent different phonemes. According to Kaani and Joshi (2013), English is considered one of the most orthographically non-transparent (opaque) among alphabetic languages, thereby posing the most difficult to master, while African local languages, similar to Finnish, are considered most transparent among alphabetic orthographies due to their consistency in both reading and writing directions.

Orthographic consistency facilitates more rapid development of phonemic awareness and thus the basic reading skill. Thus, the most appropriate instruction methods focus on teaching the connections between spoken and written language at the level of phonemes and graphemes (Lyytinen, 2015). Automatizing the retrieval of the phoneme-grapheme correspondences is a necessary precursor to the development of effective decoding skills and reading fluency, which, in turn, are essential for the development of reading comprehension skills. A fluent reading skill of a familiar language facilitates learning of more complicated orthographies such as English, French and Portuguese (Abadzi, 2013). 
Other studies (e.g., Ojanen, et. al., 2013) have observed that early grade learners confuse some of the English letter-names with letter-sounds in Zambian language, e.g., /a/ and /i/ and /e/ most likely due to errors originating from teaching because all teachers (at 2016) learned to read English when they were in school. This may slow down learning of correct local language letter-sounds and consequently delay literacy acquisition. The very high portion of zero scorers in all languages and program groups documents a highly compromised implantation of the instruction leading to such failure of acquiring even the very basic knowledge needed for the foundation skill of reading among most of the learners.

\section{Limitations of the study and suggestions for further research}

The letter-sound knowledge sub-test needs to be interpreted with caution. First, the huge number of zero scorers revealed that the implementation of neither program was far from reaching a satisfactory level. The reliability of reading skill scoring might also have been less than ideal in that a child could obtain zero score he or she remained silent on prompt or said the letter names in English. Future studies should therefore explore ways to improve reading instruction and testing procedures. The testing procedure of EGRA has to be inspected to see the problems that it causes and develop assessment tools that can respond to remedial needs through classroom-based assessment and help to diagnose learners with learning difficulties.

Second, the children's test performance was not recorded by audio or video, so was not possible to cross-check the assessors' scoring accuracy. Future studies should explore the use of 
recordings to which learners can listen and answer questions. This is in order to standardize the testing procedures.

Other limitations were that the study did not cover details of the teachers' skill in teaching familiar languages for PRP or PLP, nor the home language or fluency of the teachers in the languages they were teaching. Future studies should assess the teachers' fluency in teaching familiar languages so that both the learners' and teachers' skills are considered in the test result.

\section{Conclusion}

Comparing the two programs, the results from this study may be interpreted as being in favour of PLP which has placed much emphasis on teaching the basic key components of learning to read (phonemic awareness, phonics, fluency, vocabulary and reading comprehension), and has also placed much emphasis on the phonics approach for teaching reading. However, the lesson to learn from this research is that the significant differences between PRP and PLP demonstrate small effect sizes, and both programs had high proportions of zero scores. This means that more needs to be done in order to ensure that PLP becomes more effective for better results than results established by this research. This study reminds researchers and educationalists to take a keen interest in the effects of literacy programs implemented in Zambia. Working closely with the Ministry of General Education researchers can follow up implementation and suggest opportunities for development and improvements in Zambia's most constrained literacy environments such as the use of Graphogame that has been piloted in Zambia and has shown positive results. 


\section{Acknowledgements}

We would like to show our gratitude to Dr. Tassew Zewdie, Chief of Party for USAID/Read To Succeed Project and Guy Bostock on behalf of Research Triangular Institute International for their interest and support for this research. We thank University of Jyvaskyla Department of Psychology for scholarship grants to the key lead author

of this manuscript. We thank Professor Ulla Richardson and Suzanne Puhakka from Agora Center University of Jyvaskyla and Professor Timo Ahonen from Niilo Mäki for comments that greatly improved the manuscript. We thank Center for Promotion of Literacy in Sub-Sahara Africa (CAPOLSA) for sharing their wisdom during the course of this research. We would like to extend our gratitude to the Ministry of General Education Zambia for allowing this research to be conducted in the schools. Finally, we thank all the assessors from University of Zambia, Department of Psychology and former Ministry of General Education staff who conducted early grade reading (EGRA) assessment tests in 2014 and of course the children and their teachers who participated in this study. 


\section{REFERENCES}

Abadzi, H. (2013). Efficient learning for the poor: Insights from the frontier of Cognitive Neuroscience. Washington, DC: The World Bank. From https://openknowledge.worldbank.org/handle/10986/7023

Aro, M. (2004). Learning To Read: The Effect of Orthography. Jyväskylä. Studies in Education, Psychology and Social Research, 237.

Aro, M. \& Wimmer, H. (2003). Learning to read: English in comparison to six more regular Orthographies, Applied Psycholinguistics, 24(4), pp. 621-635. Doi:

10.1017/S0142716403000316

Clark, A. (2013). Phonics-based Reading Vs. The Whole Language Approach. 13 August 2013. Published in Reading.

Cohen, J. (1992). A power primer. Psychological Bulletin, 112(1), 155.

Dong, Y., \& Peng, C. J. (2013). Principled missing data methods for researchers. Springerplus, 2(222), 1-17.

Dubeck, M. M. \& Gove, A. (2015). The Early Grade Reading Assessment (EGRA): Its theoretical foundation, purpose, and limitations. International Journal of Educational Development, 40, 315-322. http://dx.doi.org/10.1016/j.ijedudev.2014.11.004

Field, A. P. (2009). Discovering statistics using SPSS: (and sex, drugs and rock ' $n$ ' roll) (3rd ed.). Los Angeles: SAGE Publications.

Global Education and Monitoring Report (2016). If you don't understand, how can you read? Policy Paper 24. Paris: UNESCO. Retrieved from http://unesdoc.unesco.org/images/0024/002437/243713e.pdf

Hall, M.A. (1970). Teaching English as a language experience. Colombus, OH: Charles Merrill.

Holm, S. (1979). A simple sequentially rejective multiple test procedure. Scandinavian journal of statistics, 65-70.

Kaani, B. \& Joshi, R. M. (2013). Effects of Orthographic Opacity on Spelling Proficiency: A Cross linguistic Comparison of Nyanja and English Orthographies. Insights on Learning Disabilities 10(2), 45-66.

Lowry, R. (2016). The Significance of the Difference Between Two Independent Proportions. Retrieved from http://vassarstats.net/propdiff_ind.html 
Lyytinen, H., Erskine, J., Hämäläinen, J., Torppa, M., \& Ronimus, M. (2015). Dyslexia - Early Identification and Prevention: Highlights from Jyväskylä Longitudinal Study of Dyslexia.

Current Developmental Disorders Reports, 2(4), 330-338. DOI: 10.1007/s40474-015-0067-1.

Matafwali, B. \& Bus, A. G. (2013). Lack of Language of Proficiency: A cause of reading in Zambia. Insights of Learning Disabilities 10(2), 31- 44.

Ministry of Education, (1996). Educating Our Future, National Policy on Education. Lusaka: Zambia Education Publishing House.

Ministry of Education, Science, Vocational Training and Early Education (2013), Zambia Education Curriculum Framework. Lusaka: Curriculum Development Center.

Ojanen, E., Kujala, J., Richardson, U. \& Lyytinen, H. (2013). Technology-Enhanced Literacy Learning in Zambia: Observations from a Multilingual Literacy Environment. Insights on Learning; Disabilities: From Prevailing Theories to Validated Practices, 2, 103-127

Ohannessian, S., \& Kashoki, E.(eds.) (1978). Language in Zambia. London: International African Institute.

Research Triangle Institute (RTI) International, (2012). Pupil performance, Pedagogic, Practice And School management: An SSME pilot in Zambia. USAID EdDataII, Task Order No. 7. Retrieved from http://pdf.usaid.gov/pdf_docs/PA00HVCV.pdf

Research Triangle Institute (RTI) International, (2015). National Assessment Survey of Learning Achievement at Grade 2. Lusaka: Results for Early Grade Reading and Mathematics in Zambia. Retrieved $28^{\text {th }}$ April 2016 from http://pdf.usaid.gov/pdf_docs/PA00KR25.pdf

Seymour, P., Aro, M. \& Erskine, J. M. (2003). Foundation literacy acquisition in European Orthographies. British Journal of Psychology, 94, 143-174.

Serpell, R. (2014). Contextual responsiveness: an enduring challenge for educational assessment in Africa. Journal of Intelligence, 17, 4(1), 1-19. Doi:10.3390/jintelligence4010003

Serpell, R. \& Simatende, B. (2016). Contextual Responsiveness: An Enduring Challenge for Educational Assessment in Africa. Journal of Intelligence, 4 (3).

DOI:10.3390/jintelligence4010003.

Tambulukani, G. \& Bus, A (2011). Linguistic Diversity: The Cause of Reading Problems Among Learners in Zambian Primary Schools, Journal of Applied Linguistics, Oxford University Press, Oxford

Taylor, M. (2000). Center for Adult English Acquisition. Job link 2000. June 1992.

USAID Read To Succeed Project. (2015). Lusaka: Midline Survey Report. 